\title{
The epigenetic agents suberoylanilide hydroxamic acid and 5-AZA-2' deoxycytidine decrease cell proliferation, induce cell death and delay the growth of MiaPaCa2 pancreatic cancer cells in vivo
}

\author{
JOHANA M. SUSANTO ${ }^{1}$, EMILY K. COLVIN ${ }^{1}$, MARK PINESE ${ }^{1}$, DAVID K. CHANG ${ }^{1,2}$, MARINA PAJIC ${ }^{1}$, \\ AMANDA MAWSON $^{1}$, C. ELIZABETH CALDON ${ }^{1}$, ELIZABETH A. MUSGROVE ${ }^{1}$, SUSAN M. HENSHALL ${ }^{1}$, \\ ROBERT L. SUTHERLAND ${ }^{1}$, ANDREW V. BIANKIN ${ }^{1-3}$ and CHRISTOPHER J. SCARLETT ${ }^{1,4}$ \\ ${ }^{1}$ Cancer Research Program, Garvan Institute of Medical Research, Sydney, NSW 2010; ${ }^{2}$ Division of Surgery, \\ Bankstown Hospital, Sydney, NSW 2200; ${ }^{3}$ St. Vincent's Clinical School, Faculty of Medicine, \\ The University of New South Wales, Sydney, NSW 2052; ${ }^{4}$ School of Environmental and \\ Life Sciences, University of Newcastle, Ourimbah, NSW 2258, Australia
}

Received July 22, 2014; Accepted September 7, 2014

DOI: 10.3892/ijo.2015.2894

\begin{abstract}
Despite incremental advances in the diagnosis and treatment for pancreatic cancer (PC), the 5-year survival rate remains $<5 \%$. Novel therapies to increase survival and quality of life for PC patients are desperately needed. Epigenetic therapeutic agents such as histone deacetylase inhibitors (HDACi) and DNA methyltransferase inhibitors (DNMTi) have demonstrated therapeutic benefits in human cancer. We assessed the efficacy of these epigenetic therapeutic agents as potential therapies for PC using in vitro and in vivo models. Treatment with HDACi [suberoylanilide hydroxamic acid (SAHA)] and DNMTi [5-AZA-2' deoxycytidine (5-AZA-dc)] decreased cell proliferation in MiaPaCa2 cells, and SAHA treatment, with or without 5-AZA-dc, resulted in higher cell death and lower DNA synthesis compared to 5-AZA-dc alone and controls (DMSO). Further, combination treatment with SAHA and 5-AZA-dc significantly increased expression of $\mathrm{p} 21^{\mathrm{WAF} 1}$, leading to $\mathrm{G} 1$ arrest. Treatment with epigenetic agents delayed tumour growth in vivo, but did not decrease growth of established pancreatic tumours. In conclusion, these data demonstrate a potential role for epigenetic modifier drugs for
\end{abstract}

Correspondence to: Professor Andrew V. Biankin, Cancer Research Program, Garvan Institute of Medical Research, 384 Victoria St, Sydney, NSW 2010, Australia

E-mail: a.biankin@garvan.org.au

Abbreviations: PC, pancreatic cancer; HDACi, histone deacetylase inhibitors; DNMTi, DNA methyltransferase inhibitors

Key words: pancreatic cancer, histone deacetylase inhibitor, DNA methyltransferase inhibitor the management of PC, specifically in the chemoprevention of $\mathrm{PC}$, in combination with other chemotherapeutic agents.

\section{Introduction}

Pancreatic cancer (PC) is the fourth most common cause of cancer death in Western societies with a 5-year survival of $<5 \%$ (1-6). PC often presents asymptomatically, and as a consequence is advanced in the majority of cases at diagnosis $(5,7)$. Surgical resection currently offers the only option for long-term survival, however, only $20 \%$ of patients are suitable for surgical intervention $(8,9)$. Current chemotherapeutic and radiation treatments have also met with limited success $(5,9)$. Novel diagnostic and therapeutic strategies are urgently needed to improve outcomes for this disease.

Epigenetic therapeutic agents, such as histone deacetylase inhibitors (HDACi) and DNA methyltransferase inhibitors (DNMTi), have demonstrated efficacy in the treatment of cutaneous T-cell lymphoma (CTCL) (10-12) and myelodysplastic syndrome (MDS) $(13,14)$. Preclinical studies of epigenetic modulating drugs in other cancers have also demonstrated antitumour activity with tolerable toxicity, suggesting a potential role for these drugs in cancer treatment (15-19). HDACi and DNMTi are thought to act by regulating gene expression and remodelling the chromosome structure, which may lead to cell cycle arrest and cell death $(20,21)$.

HDACi induce accumulation of acetylated histones, resulting in the relaxation of chromatin structure to promote access of transcriptional machinery (22). Induction of p21 ${ }^{\mathrm{WAF} 1}$ expression after treatment with HDAC $\mathrm{i}$ is common and appears to play a major role in arresting the growth of transformed cells (23-26). DNMTi reduce genomic DNA methylation by binding to DNA methyltransferases (DNMT) after being incorporated into newly synthesized DNA $(16,27)$. DNA methylation, a major epigenetic mechanism of gene regulation, 
is usually associated with gene silencing (28). Treatment with DNMTi reverses aberrant DNA methylation and thus reactivates the transcription of many genes, including putative tumour suppressor genes $(16,28,29)$. The re-expression of tumour suppressor genes is thought to contribute, at least in part, to the DNMTi anticancer effect $(29,30)$. In acute myeloid leukemia cells, DNMTi alter cell cycle progression, reduce cell proliferation and induce apoptosis (16). Treatment combining DNMTi with HDACi results in synergistic cell death, which may reflect re-expression of silenced genes as well as the potentiation of cell death through acetylation of non-histone proteins $(10,31)$.

Previous studies have identified several genes with tumour suppressor properties that are epigenetically regulated in PC (32-35), including the regulation of mucin expression [MUC1 (36), MUC2 (37) and MUC4 (38)], which is associated with carcinogenesis and tumour invasion (36-39). The mechanism of epigenetic alterations in $\mathrm{PC}$ is poorly understood (40). Treatment of PC cells with HDACi induces cell death and enhances the apoptotic effects of gemcitabine (24). In the gemcitabine-resistant PC cell line, PANC1, treatment with suberoylanilide hydroxamic acid (SAHA) restores sensitivity to gemcitabine (24). Treatment with 5-AZA-2' deoxycytidine (5-AZA-dc) restores the expression of BNIP3 and induces hypoxia-mediated cell death (35). Together, these data suggest potential for epigenetic modulating drugs in the treatment and management of PC.

\section{Materials and methods}

Cell culture. MiaPaCa2 cells were cultured in DMEM supplemented with $10 \%$ FBS and $2.5 \%$ horse serum according to American Type Culture Collection (ATCC) protocols. Human pancreatic ductal epithelial (HPDE) cells, a gift from Dr Ming-Sound Tsao, were used as a normal control and cultured in keratinocyte serum-free medium (KSF) supplemented with $50 \mathrm{mg} / \mathrm{ml}$ bovine pituitary extract and $5 \mathrm{ng} / \mathrm{ml}$ epidermal growth factor (41). These cell lines were maintained in a humidified atmosphere of $5 \% \mathrm{CO}_{2}$ at $37^{\circ} \mathrm{C}$.

5-AZA-dc and SAHA treatment. MiaPaCa2 cells were plated at $1.5 \times 10^{5}$ cells/well in 6 -well plates for protein/nucleic acid harvest; or at $3.9 \times 10^{5}$ cells in T25 flasks for flow cytometry analysis (Day 0). The cells were treated as follows: i) treated on Day 1 with $300 \mu \mathrm{M}$ of 5-AZA-dc (Sigma-Aldrich) and harvested on Day 6; ii) treated on Days 1-3 and Day 5 with $5 \mu \mathrm{M}$ of SAHA (Cayman Chemical) and harvested on Day 6; iii) treated on Day 1 with 5-AZA-dc, Day 2, 3 and 5 with SAHA and harvested on Day 6. Untreated MiaPaCa2 and HPDE cells were used as controls. During treatment, the media was changed daily, and cells were washed twice with cold PBS prior to nucleic acid and/or protein extraction.

MTS assay. An MTT assay was performed using CellTiter $96^{\circledR}$ AQueous Non-Radioactive Cell Proliferation Assay according to the manufacturer's protocol (Promega Corporation). MiaPaCa2 and HPDE cells were plated at a density of $0.5 \times 10^{4}$ cells/well in 96-well plates to measure cell proliferation. Cells were treated on Days 1-5 with SAHA (Cayman Chemical) at a concentration of 1,3 or $5 \mu \mathrm{M}$. Untreated
$\mathrm{MiaPaCa} 2$ and HPDE cells were included in each plate as controls. Each treatment group was plated in triplicate and repeated at least three times. Media was changed daily during treatment. An additional untreated plate was prepared as a baseline. Absorbance was measured at $490 \mathrm{nM}$.

BrdU and PI staining. MiaPaCa2 cells were pulsed with bromodeoxyuridine (BrdU) (Sigma-Aldrich) for $1 \mathrm{~h}$ prior to harvesting. Cells were harvested and fixed in $70 \%$ ethanol overnight at $4^{\circ} \mathrm{C}$ before $\mathrm{BrdU}$ and propidium iodide (PI) (Sigma-Aldrich) staining. The next day, ethanol was removed and cells resuspended in PBS/1\% Tween-20 (PBST) followed by DNA denaturation using $1.5 \mathrm{M}$ $\mathrm{HCl}$ for $20 \mathrm{~min}$. The cells were in PBST (3X), resuspended in $100 \mu \mathrm{l}$ PBST, followed by the addition of $5 \mu \mathrm{l}$ of $250 \mu \mathrm{g} / \mathrm{ml}$ FITC-anti-BrdU (MAB3262F; Chemicon) for $1 \mathrm{~h}$ at $37^{\circ} \mathrm{C}$ in the dark. After incubation, cells were washed with $1 \mathrm{ml}$ cold PBST and resuspended in $470 \mu \mathrm{l}$ PBST. PI $(5 \mu \mathrm{l}$ of $1 \mathrm{mg} / \mathrm{ml})$ and RNase A (25 $\mu \mathrm{l}$ of $10 \mathrm{mg} / \mathrm{ml}$ ) (Sigma-Aldrich) were added and mixed gently by pipetting. The cells were incubated between 1-4 $\mathrm{h}$ in the dark at room temperature. Prior to running on the BD FACSCalibur ${ }^{\mathrm{TM}}$ or BD FACSCanto ${ }^{\mathrm{TM}}$ flow cytometer (BD Biosciences), cells were syringed gently to avoid cell clumping. Flow cytometry data were analysed using either BD CellQuest ${ }^{\mathrm{TM}}$ (BD Biosciences), or FlowJo 8.7.3 or 8.8.2 (Tree Star, Inc.).

Protein extraction. Cell lysis and protein extraction from cell lines were performed on ice. Media was removed and cell monolayers washed twice with cold PBS. Lysis buffer $(50 \mu \mathrm{l})$ containing protease inhibitors $(0.5 \%$ deoxycholate, $150 \mathrm{mM} \mathrm{NaCl}, 1 \%$ sodium pyrophosphate, $50 \mathrm{mM}$ Tris pH 8.0, 0.1\% SDS, $10 \%$ glycerol, 5 mM EDTA, $20 \mathrm{mM} \mathrm{NaF}$, $10 \mu \mathrm{g} / \mathrm{ml}$ apoprotinin, $10 \mu \mathrm{g} / \mathrm{ml}$ leupeptin, $1 \mathrm{mM}$ phenylmethylsufonyl fluoride (PMSF), $200 \mu \mathrm{M}$ sodium orthovanadate; Sigma-Aldrich) was added to each well of a 6-well plate. The cells were scraped and transferred to microcentrifuge tubes, vortexed and centrifuged at $13,000 \mathrm{rpm}$ for $5 \mathrm{~min}$ at $4^{\circ} \mathrm{C}$. The supernatant was collected and 2-5 $\mu \mathrm{l}$ of the supernatant was aliquoted for protein quantitation. The remaining supernatant was stored at $-80^{\circ} \mathrm{C}$. Protein quantification was performed using the Bio-Rad Protein Assay kit according to the manufacturer's instructions.

Western blot analysis. Following normalization for protein concentration, SDS sample buffer was added and lysates denatured at $70^{\circ} \mathrm{C}$ for $10 \mathrm{~min}$, protein was separated using $4-12 \%$ Bis-Tris NuPAGE ${ }^{\circledR}$ precast gels (Invitrogen Life Technologies) and transferred to polyvinylidene fluoride (PVDF) membranes according to the manufacturer's protocols. Non-specific binding was blocked in $10 \%(\mathrm{w} / \mathrm{v})$ skim milk powder in TBS/Tween-20 [10 mM Tris pH 7.4, $150 \mathrm{mM} \mathrm{NaCl}, 0.1 \%$ (v/v) Tween-20; TBST]. Membranes were incubated with primary antibodies diluted in TBS/BSA solution (10 mM Tris $\mathrm{pH} 7.4$, $150 \mathrm{mM} \mathrm{NaCl}, 5 \%$ w/v BSA, $0.02 \%$ azide). Table I contains the list of primary antibodies and their incubation conditions. Membranes were washed in TBST for $30 \mathrm{~min}$, then incubated for $1 \mathrm{~h}$ at room temperature with HRP-conjugated anti-rabbit or anti-mouse secondary antibody $(1: 2,000$; Amersham Pharmacia Biotech) in 5\% (w/v) skim milk 
Table I. Primary antibodies for western blot analysis.

\begin{tabular}{|c|c|c|c|}
\hline Primary & Dilution & Manufacturer & Incubation \\
\hline$\beta$-actin (AC-15; A5441) & $1: 40,000$ & Sigma-Aldrich & $1 \mathrm{~h}$ RT \\
\hline \multicolumn{4}{|l|}{ Cyclin } \\
\hline E (He12; SC-247) & $1: 500$ & $\begin{array}{l}\text { Santa Cruz. } \\
\text { Biotechnology, Inc. }\end{array}$ & $\mathrm{O} / \mathrm{N} 4^{\circ} \mathrm{C}$ \\
\hline A (C19; SC-596) & $1: 500$ & $\begin{array}{l}\text { Santa Cruz } \\
\text { Biotechnology, Inc. }\end{array}$ & $\mathrm{O} / \mathrm{N} 4^{\circ} \mathrm{C}$ \\
\hline D1 (DCS-6) & $1: 100$ & Novocastra & $\mathrm{O} / \mathrm{N} 4^{\circ} \mathrm{C}$ \\
\hline B1 (V152; 4135) & $1: 2,000$ & $\begin{array}{l}\text { Cell Signaling } \\
\text { Technology, Inc. }\end{array}$ & $\mathrm{O} / \mathrm{N} 4^{\circ} \mathrm{C}$ \\
\hline p21 WAF1 (610234) & $1: 1,000$ & BD Biosciences & $\mathrm{O} / \mathrm{N} 4^{\circ} \mathrm{C}$ \\
\hline
\end{tabular}

RT, room temperature; $\mathrm{O} / \mathrm{N}$, overnight.

powder in TBST. Membranes were washed for $30 \mathrm{~min}$ in TBST before proteins were visualized using the Enhanced Chemiluminescence (ECL) detection system (Perkin Elmer) on X-ray film (Fujifilm Medical Systems USA). Cell cycle marker (cyclin E, A, D1, B1 and $\mathrm{p} 21^{\mathrm{WAF} 1}$ ) protein levels were determined relative to $\beta$-actin by densitometry using ImageJ software [National Institutes of Health (NIH)] and normalized to DMSO-treated control samples.

In vivo study of the efficacy of epigenetic therapeutic agents in a xenograft model of $P C$. Ethics approval was obtained from Garvan Institute and St. Vincent's Hospital Animal Ethics Committee to examine the effect of epigenetic therapeutic agents in a mouse xenograft model of PC (Protocol no. 07/06).

$\mathrm{MiaPaCa} 2 \mathrm{PC}$ cells were injected subcutaneously into female athymic nude mice (BALB/c nu/nu) (6-8 weeks old, mean weight of $16 \mathrm{~g}$ ). Prior to injection, $\mathrm{MiaPaCa} 2$ cells were harvested, counted and diluted to the appropriate concentration in cold media. For each mouse, $1.0 \times 10^{6} \mathrm{MiaPaCa} 2$ cells were diluted in 1:1 mixture of cold media and BD Matrigel ${ }^{\mathrm{TM}}$ Basement Membrane Matrix (BD Biosciences) to a total volume of $100 \mu \mathrm{l}$ and kept on ice until injection.

The mice were divided into three treatment groups: i) vehicle (control) $(n=5)$, ii) SAHA alone $(n=5)$; and iii) 5-AZA-dc and SAHA (n=5). 5-AZA-dc was administered in a single dose at a concentration of $0.25 \mathrm{mg} / \mathrm{kg}$, followed by daily intraperitoneal administration of SAHA for 21 days at a dose of $50 \mathrm{mg} / \mathrm{kg}$ (in a maximum volume of $0.1 \mathrm{ml}$ ). Treatment began 1 week after the injection of MiaPaca2 cells to examine the ability of the drugs to prevent tumour growth (Prevention Studies); or once a solid tumour was present to test the ability of the drugs to reduce tumour growth (Therapeutic Studies). The mice were euthanased upon cessation of drug treatments and tumour weight was measured. The pancreas, abdominal cavity, mesentery, spleen and liver were assessed for the presence of metastases. Tumour size was measured, and tumour volume was calculated using the formula $1 / 2$ length $\mathrm{x}$ breadth $\mathrm{x}$ width (42). The in vivo experiments were performed in duplicate, with tumour measurements from each experiment combined for statistical analysis.
Statistical analysis. All in vitro experiments were carried out at least in triplicate, and the in vivo studies in duplicate. Mean, standard deviation and Student's t-test were calculated using Microsoft Excel. Statistical analyses of univariate analysis of variance (ANOVA), Tukey's post hoc tests and calculation of $95 \%$ confidence interval were performed using SPSS16.0 (SPSS Inc.) and/or R v.2.10.1 (R Foundation for Statistical Computing).

\section{Results}

Treatment with SAHA and 5-AZA-dc decreases cell proliferation in MiaPaCa2 cells. Treatment with SAHA alone, or in combination with 5-AZA-dc, resulted in higher cell death and lower DNA synthesis (Fig. 1A) compared to 5-AZA-dc alone or DMSO-treated cells. In MiaPaCa2 cells, treatment with SAHA was more effective in inducing cell death than treatment with 5-AZA-dc ( $\mathrm{p}=0.002$ and $\mathrm{p}=0.008$ respectively), while SAHA treatment alone was not significantly different to combination therapy ( $\mathrm{p}=0.019$; Fig. $1 \mathrm{~A})$. The dramatic effect of SAHA may potentially be due to a global effect of chromatin remodelling in regulation of cellular function, as defective histone dynamics during $\mathrm{S}$ phase, DNA repair and mitosis result in cell cycle arrest and cell death (43).

DNA synthesis levels, as measured by BrdU incorporation, were significantly reduced upon treatment with SAHA, either alone $(\mathrm{p}=0.001)$ or in combination with 5-AZA-dc $(\mathrm{p}=0.005)$, while treatment with 5-AZA-dc alone had no significant effect compared to DMSO-treated cells (Fig. 1A). These data correlate with higher levels of $\mathrm{p} 21^{\mathrm{WAF} 1}$ observed in SAHA and SAHA/5-AZA-dc combination-treated samples relative to control and 5-AZA-dc-treated cells (Fig. 1B), which is consistent with findings in other cancer types (44).

Western blot analysis of cell cycle markers cyclin E1, B, A, D1 and $\mathrm{p} 21^{\mathrm{WAF} 1}$ revealed that MiaPaCa2 cells treated with 5-AZA-dc alone expressed higher cyclin E protein compared to control (DMSO) cells (Fig. 1B). Cells treated with SAHA, alone or in combination with 5-AZA-dc, expressed higher levels of cyclin E1 and significantly higher $\mathrm{p} 21^{\mathrm{WAF} 1}$ protein levels that could be contributing to G1/S-phase cell cycle arrest (45).

MiaPaCa2 cells are more sensitive than HPDE cells to treatment with SAHA. Previous studies have reported that normal cells are more tolerant to epigenetic drug therapy compared to cancer cells (46-49). We investigated this premise using the 'normal' pancreatic ductal cell line, HPDE, and MiaPaCa2 cells.

Increasing SAHA concentration significantly decreased cell proliferation in both MiaPaCa2 $(\mathrm{p}<0.0001)$ and HPDE cells ( $<<0.0001$; Fig. 1C). However, the cell lines demonstrated different cell proliferation rates in response to drug treatment, suggesting that $\mathrm{MiaPaCa} 2$ cells are more sensitive to epigenetic modifying agents than HPDE cells $(\mathrm{p}=0.034)$.

Treatment with SAHA and/or 5-AZA-dc increases expression of $p 21^{\text {WAFI }}$. Induction of $\mathrm{p} 21^{\mathrm{WAF} 1}$ expression upon treatment with epigenetic drugs reportedly induces cell cycle arrest in some cancer types, including $\mathrm{MiaPaCa} 2$ cells. The induction of $\mathrm{p} 21^{\mathrm{WAF} 1}$ expression in HPDE and MiaPaCa2 cells after treatment with SAHA, with or without 5-AZA-dc (Fig. 1D), 
A

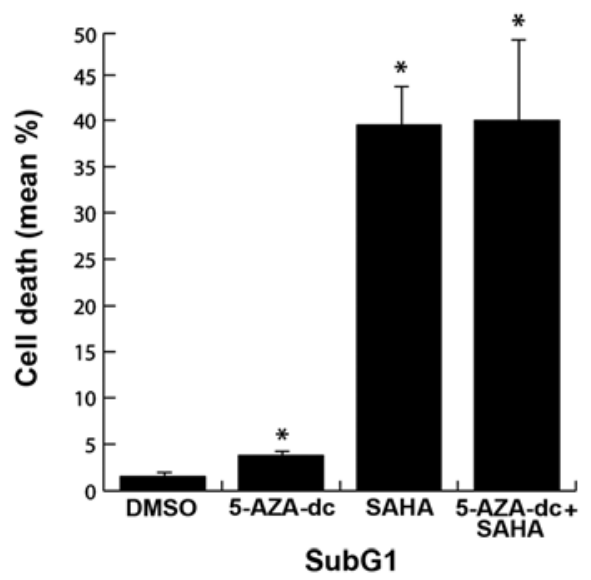

C

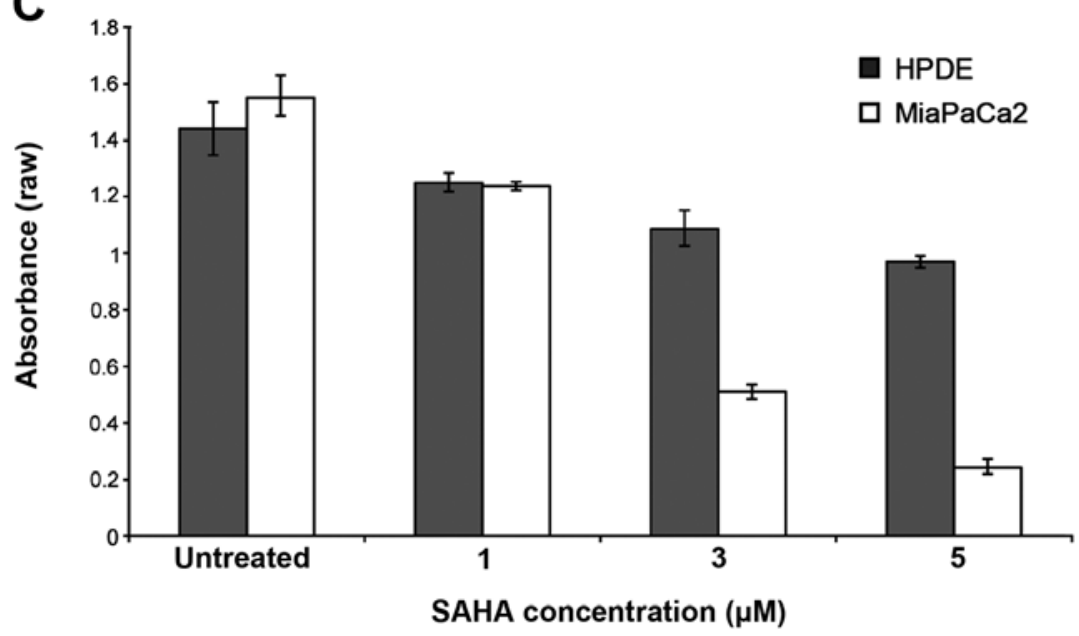

B

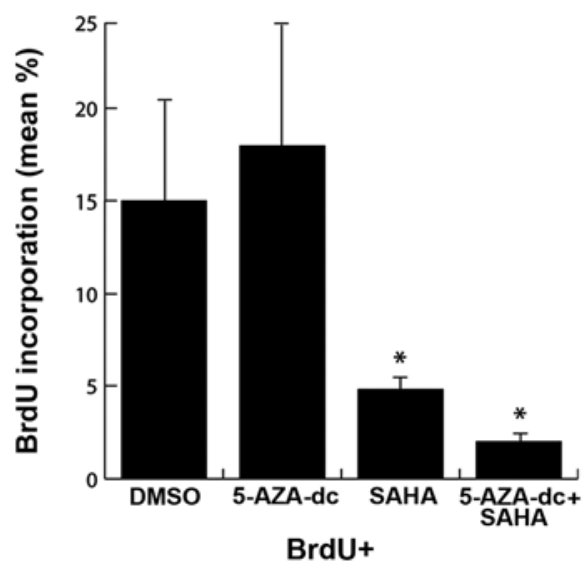

D

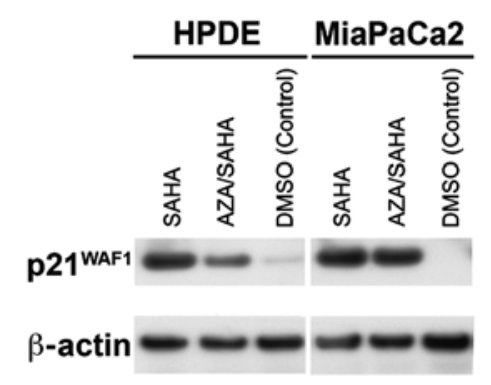

Figure 1. (A) Effect of 5-AZA-2' deoxycytidine (5-AZA-dc) and/or suberoylanilide hydroxamic acid (SAHA) treatment on cell proliferation and DNA synthesis in MiaPaCa2 cells. Cell proliferation: MiaPaCa2 cells treated with 5-AZA-dc, SAHA, or combination SAHA/5-AZA-dc significantly increased cell death, as determined by the SubG1 population compared to control cells. DNA synthesis: MiaPaCa2 cells treated with SAHA, with or without 5-AZA-dc reduced DNA synthesis compared to treatment with 5-AZA-dc alone and control (DMSO), as determined by bromodeoxyuridine (BrdU) incorporation. ${ }^{*} \mathrm{P}<0.05$ compared to untreated control; Student's t-test. (B) Cell cycle markers 3 days post-treatment with SAHA and/or 5-AZA-dc. Treatment with 5-AZA-dc alone increased the expression of cyclin $\mathrm{E}$ and $\mathrm{p} 21^{\mathrm{WAF}}$ compared with controls, while treatment with SAHA alone also led to higher expression of $\mathrm{p} 21^{\mathrm{WAF} 1}$. The combination treatment with 5-AZA-dc and SAHA increased $\mathrm{p} 21^{\mathrm{WAFl}}$ expression and increased the expression of cyclin E1, but did not alter expression of cyclin B, A and D1. (C) Efficacy of SAHA treatment on MiaPaCa2 vs. human pancreatic ductal epithelial (HPDE) cell proliferation. Treatment with SAHA reduced MiaPaCa2 and HPDE cell proliferation. MiaPaCa2 cells were more sensitive to SAHA than were HPDE cells. Data are expressed as raw absorbance values $\pm 95 \%$ CI. (D) $\mathrm{p} 21^{\mathrm{WAF} 1}$ expression in HPDE and MiaPaCa2 cells treated with 5-AZA-dc and/or SAHA. Treatment with SAHA alone, and in combination with 5-AZA-dc, increased expression of $\mathrm{p} 21^{\mathrm{WAFl}}$ compared to control cells (DMSO-treated cells).

was associated with decreased proliferation (Fig. 1C), suggesting that the induction of $\mathrm{p} 21^{\mathrm{WAF} 1}$ expression following treatment with epigenetic drugs may contribute to decreased cell proliferation.

The efficacy of 5-AZA-dc and SAHA in a pancreatic xenograft model

Prevention studies. Using a subcutaneous xenograft model of PC we investigated the efficacy of pharmacological epigenetic modulation in the prevention of tumour growth. Treatment with SAHA and/or 5-AZA-dc significantly increased the tumour lag period compared to control $(\mathrm{p}=0.001$ and $\mathrm{p}<0.001$ respectively; Fig. 2A), while the lag period between the two treatment groups (5-AZA-dc/SAHA and SAHA alone) was similar ( $\mathrm{p}=0.882$; Fig. 2A). The lag period was defined as the time required for the tumour volume to reach $100 \mathrm{~mm}^{3}$ (indicated by the shaded area in Fig. 2A). Tumour growth rate measured after the lag cut-off point $\left(100 \mathrm{~mm}^{3}\right)$, was significantly different between groups ( $\mathrm{p}=0.001)$ (Fig. 2A), indicating an effect following treatment. However, overall tumour growth rates between the two treatment groups (5-AZA-dc/SAHA and SAHA alone) were similar. No significant difference was observed in the mean tumour weights between all groups upon completion of treatment $(\mathrm{p}=0.994)$. This suggests that after the lag period, tumours in the treated groups grew at an increased rate when compared to the control group.

Therapeutic studies. As PC is usually diagnosed at an advanced stage, we investigated the ability of epigenetic therapies to reduce tumour growth using an established subcutaneous xenograft model of PC. Similar tumour growth rates were observed 


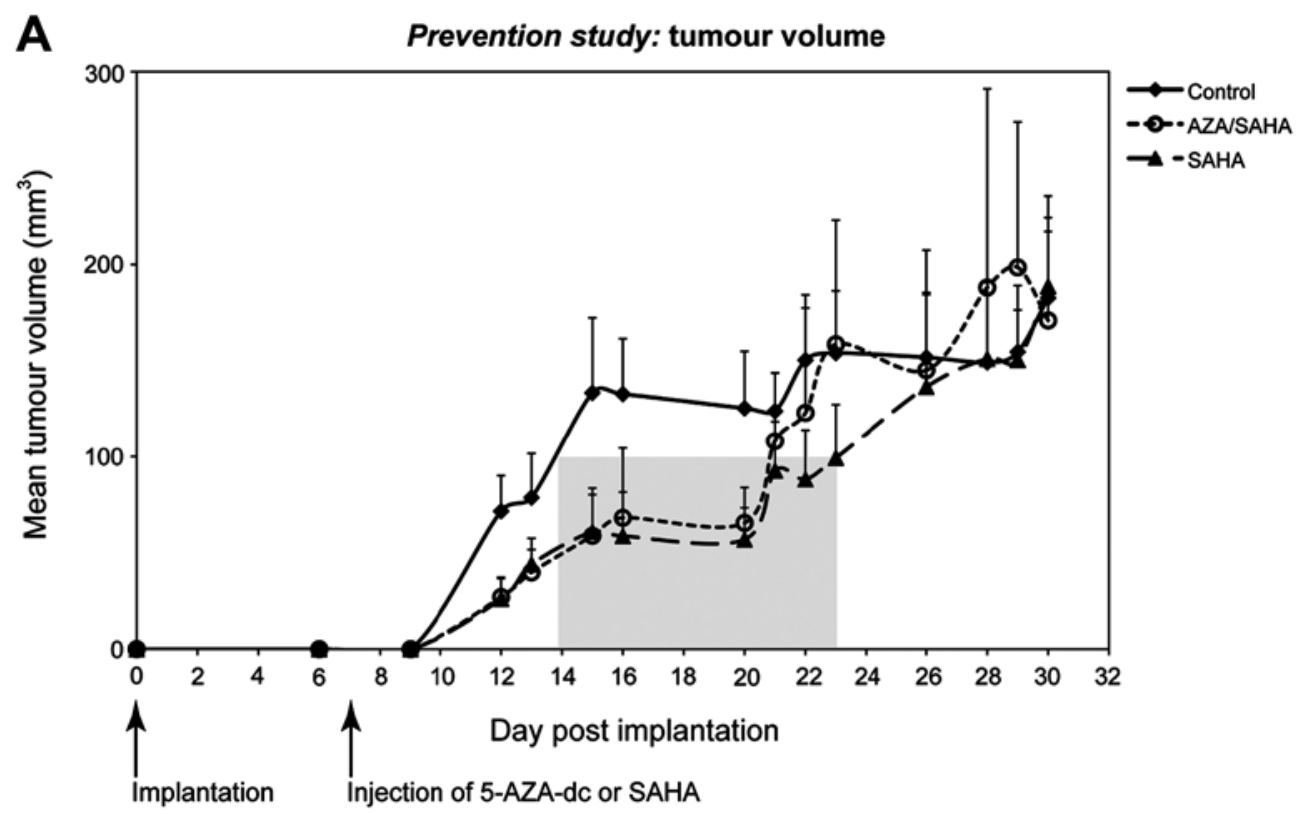

B

Therapeutic study: tumour volume

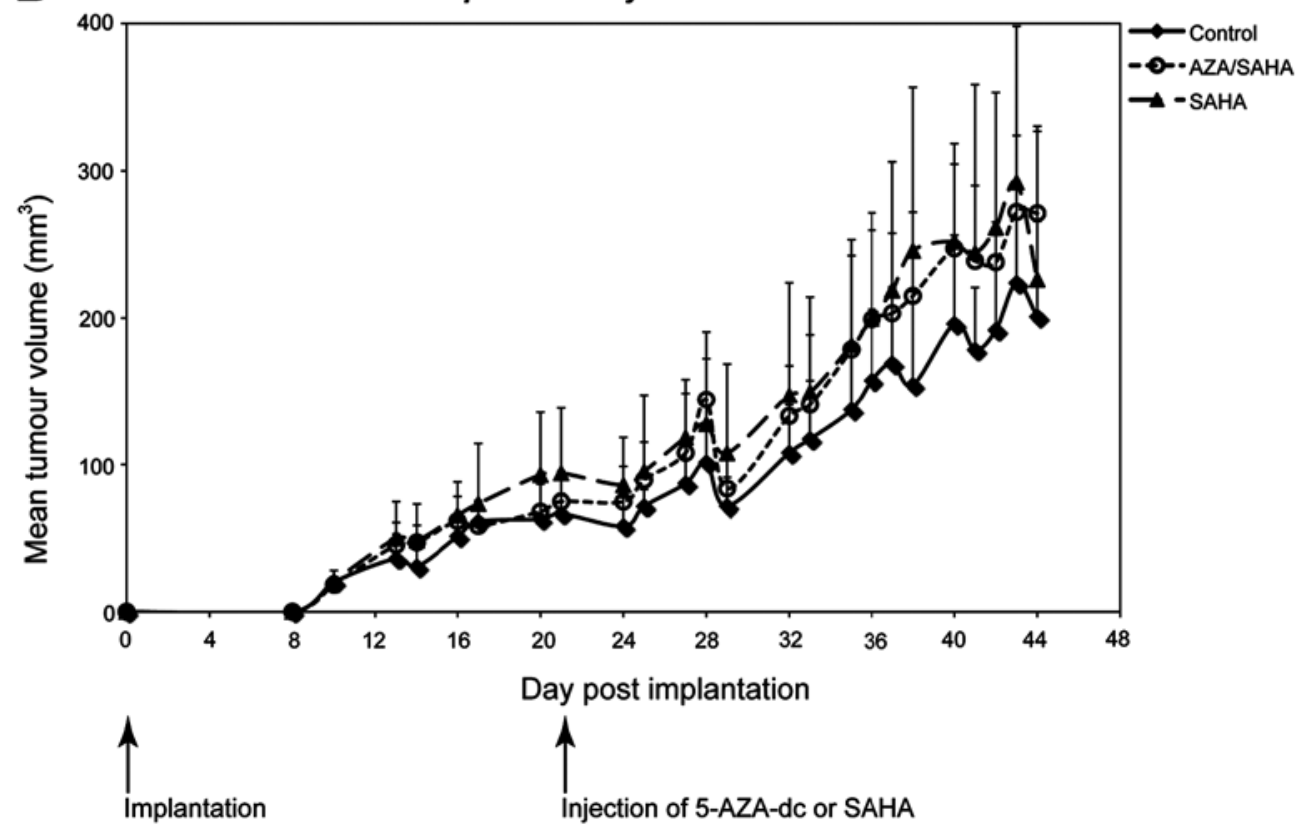

Figure 2. (A) Prevention study assessing the efficacy of 5-AZA-2' deoxycytidine (5-AZA-dc) and/or suberoylanilide hydroxamic acid (SAHA) treatment. 5-AZA-dc- and/or SAHA-treated mice had a longer lag period (time to reach $100 \mathrm{~mm}^{3}$; shaded area) compared to the control mice (treated with saline/DMSO). Similar overall tumour growth was observed in all groups. $\mathrm{P}<0.05$ compared to untreated control; analysis of variance (ANOVA). (B) Therapeutic study assessing efficacy of 5-AZA-dc and/or SAHA treatment on established tumours. Tumour growth kinetics for the duration of epigenetic treatment (Day 21-43 following subcutaneous injection of $\mathrm{MiaPaCa} 2$ cells) demonstrated no significant difference in tumour volume between treatment groups. Error bars represent the standard deviation of tumour volume.

between treatment groups and control ( $\mathrm{p}=1.000$; Fig. 2B), with no significant difference in tumour weight observed $(\mathrm{p}=0.448)$. These results indicate that in this model, treatment with SAHA, alone or in combination with 5-AZA-dc, was not effective in the treatment of established pancreatic tumours in vivo.

\section{Discussion}

Epigenetic therapies have shown promising antitumourigenic effects in some malignancies (15-19,50). These include enzyme inhibitors, specifically DNMTi and HDACi, which induce epigenetic modifications. In this study, we demonstrated that treatment of PC cells with HDACi (SAHA) in combination with DNMTi (5-AZA-dc) decreased cell proliferation and induced cell death. This may be mediated through upregulation of $\mathrm{p} 21^{\mathrm{WAF} 1}$, and is associated with cell cycle arrest, apoptosis and decreased cell proliferation $(23-26,44)$. This study also demonstrated that $\mathrm{MiaPaCa} 2$ cells were more sensitive to epigenetic drugs compared to the 'normal' HPDE pancreatic cells. 
Treatment with SAHA induced significant cell death and reduced DNA synthesis, potentially as a result of cell cycle arrest. Dysregulated histone modification, which can be promoted by HDACi, may lead to aberrant chromatin remodelling during DNA replication and repair, and mitosis $(43,51,52)$. Treatment with SAHA also induces a more open chromatin structure, increasing the susceptibility of DNA to damage $(53,54)$. These events correlate with cell cycle arrest leading to cell death $(43,51,52)$. Our study of MiaPaCa2 cells demonstrate that treatment with SAHA (HDACi) was more effective than treatment with 5-AZA-dc (DNMTi) alone. Consequently, aberrant chromatin modification following treatment with HDACi, such as SAHA, may play an important role in an anticancer effect. While the effect of HDACi in chromatin remodelling would also apply to normal cells, these are likely to be more resistant to epigenetic treatment (46-49). Therefore, this mechanism does not fully explain the anticancer effects of SAHA in MiaPaCa2 cells, or the higher tolerance of HPDE cells to epigenetic treatment.

Our data show that decreased cell proliferation and induction of cell death following treatment with SAHA and 5-AZA-dc may be mediated via upregulation of $\mathrm{p} 21^{\mathrm{WAF} 1}$. $\mathrm{p} 21^{\mathrm{WAF} 1}$ is tightly regulated by $\mathrm{p} 53$, however, as the MiaPaCa2 cell line used in this study is p53 defective, $\mathrm{p} 21^{\mathrm{WAF} 1}$ must be regulated by pathways independent of p53 [26,55,reviewed in (56)]. Previous studies have indicated that treatment with epigenetic drugs is likely to increase the expression of $\mathrm{p} 21^{\mathrm{WAF} 1}$ by regulating the chromatin structure and increasing the acetylation of histone 3 on the $\mathrm{p} 21^{\mathrm{WAF} 1}$ promoter $(12,23,26,57,58)$. More recently, Vijayaraghavalu et al demonstrated that sequential treatment of resistant breast cancer cells with 5-AZA-dc and doxorubicin induces a highly synergistic effect and caused the resistant cells to undergo G2/M cell cycle arrest, which was due to upregulation of $\mathrm{p} 21^{\mathrm{WAF} 1}$ expression. Induction of $\mathrm{p} 21^{\mathrm{WAF} 1}$ was correlated with depletion of DNA methyltransferase 1 (DNMT1), which promotes DNA methylation, suggesting that $\mathrm{p} 21^{\mathrm{WAF} 1}$ may be a methylation-suppressed gene in specific cell types (59).

A further explanation for the reduction of $\mathrm{MiaPaCa} 2$ cell proliferation observed in our study may be via the process of autophagy. Recent studies provide a strong link between HDAC inhibition and cell death by the process of autophagy $(60,61)$. In particular, Robert et al (61)showed that using valproic acid, a class I and II HDAC inhibitor, triggers Sae2 (CtIP in human) degradation by promoting autophagy that affects the DNA damage sensitivity of hdal and rpd3 mutants. While beyond the scope of this study, further experiments are necessary to address the difference in cellular response in cancer and normal cells after treatment with epigenetic drugs, such as SAHA, particularly in the way these cells regulate chromatin remodelling (61).

Since the effectiveness of epigenetic therapy is cell and context-dependent $(10,22,45,62)$, the anticancer activities in vitro, may not be translated into in vivo settings. Thus the efficacy of epigenetic drugs in vivo was assessed using a subcutaneous xenograft model of PC. The prevention studies demonstrated that treatment with SAHA, alone or in combination with 5-AZA-dc, delayed tumour progression during the early stage (lag period) of tumour development. However, the therapeutic studies demonstrated that treatment with SAHA, with or without 5-AZA-dc, did not reduce tumour growth rate nor tumour weight, indicating that treatment with epigenetic drugs alone is unlikely to be effective for the treatment of established pancreatic tumours. These data suggest that treatment with epigenetic drugs during early pancreatic carcinogenesis may provide an opportunity for the use of combination treatment with other chemotherapeutic drugs, thereby increasing the susceptibility of tumour cells to cytotoxic agents, with many studies demonstrating the synergistic effect of epigenetic drugs with existing therapeutic agents $(10,19,53,63-65)$. In particular, SAHA increases the sensitivity of PC cells to the chemotherapeutic agent gemcitabine (24). This may be particularly useful in an adjuvant setting, where a systemic adjuvant approach for resected pancreatic adenocarcinoma is the most effective means for improving overall survival (66-69). This approach has been investigated by Mohammed et al (70), who demonstrated the chemopreventative efficacy of the EGFR inhibitor, gefitinib, in delaying the progression of pancreatic intraepithelial neoplasia (PanIN) lesions to pancreatic adenocarcinoma, while not showing efficacy in advanced disease.

The exact mechanisms of the anticancer activity of combination treatments have yet to be fully elucidated, but may include regulation of chromatic structures and the induction of pro-apoptotic genes $(19,24,64,65,71)$. Our data show that the epigenetic agents modulate the cell cycle and inhibit cell growth, however, one important question arises. How effective are combination treatments likely to be if many anticancer agents need an efficient cell cycle to exert their effect? Venturelli et al recently showed that the epigenetic agent 5-AZA-cytidine sensitises cancer cells to tumour necrosis factor-related apoptosis-inducing ligand (TRAIL) by: i) inhibiting protein biosynthesis of tumour-protecting factors, thus enabling TRAIL-induced apoptosis; and ii) reversing the malignancy-associated methylation phenotype. The ability of 5-AZA-cytidine to inhibit protein biosynthesis was associated with the ability of the drug to be incorporated into cellular RNA and disrupt cellular protein biosynthesis (72). This study suggested that epigenetic drugs could exert their anticancer mechanisms via non-epigenetic modes of action, which may provide a more complete picture of the anticancer activities of combination treatments with epigenetic agents. Further, in a recent study by Shakya et al, 5-AZA-dc was administered in a mouse model of aggressive stromal-rich pancreatic adenocarcinoma, and demonstrate that 5-AZA-dc significantly reduced DNA methylation and slowed progression of pancreatic adenocarcinoma. 5-AZA-dc upregulated interferon-inducible genes (e.g., STAT1), and that treatment with 5-AZA-dc and interferon $\gamma$ had an antiproliferative effect (73). These studies support the rationale for future studies combining epigenetic agents with other anticancer agents, as well as with cytokines and immunotherapy.

In conclusion, this study illustrated that treatment with epigenetic agents decreased cell proliferation and induced cell death in PC cells, while in vivo studies demonstrated a delay in tumour progression following treatment. These data suggest that epigenetic therapy has the potential to delay early pancreatic carcinogenesis, and may have potential application in an adjuvant setting for the management of resected PC. 


\section{References}

1. Cancer Institute NSW: Cancer in New South Wales: Incidence, Mortality and Prevalence 2005. Cancer Institute NSW, Sydney, 2007.

2. National Cancer Institute: Cancer Trends Progress Report - 2007 Update. National Cancer Institute, Bethesda, MD, 2007

3. National Cancer Institute: A Snapshot of Pancreatic Cancer. National Cancer Institute, Bethesda, MD, 2007.

4. Australian Institute of Health and Welfare (AIHW) and Australasian Association of Cancer Registries (AACR): Cancer in Australia: an overview, 2008. AIHW and AACR, Canberra, 2008.

5. American Cancer Society: Cancer Facts and Figures 2008. American Cancer Society, Atlanta, GA, 2008.

6. Jemal A, Siegel R, Ward E, Hao Y, Xu J and Thun MJ: Cancer statistics, 2009. CA Cancer J Clin 59: 225-249, 2009.

7. American Cancer Society: Cancer Facts and Figures 2007. American Cancer Society, Atlanta, GA, 2007.

8. Von Hoff DD, Evans DB and Hruban RH (eds): Pancreatic Cancer. 1st edition. Jones and Bartlett Publishers, Sudbury, MA, 2005.

9. Chang DK, Merrett ND and Biankin AV; NSW Pancreatic Cancer Network: Improving outcomes for operable pancreatic cancer: is access to safer surgery the problem? J Gastroenterol Hepatol 23: 1036-1045, 2008.

10. Glaser KB: HDAC inhibitors: clinical update and mechanism-based potential. Biochem Pharmacol 74: 659-671, 2007.

11. Duvic M, Talpur R, Ni X, et al: Phase 2 trial of oral vorinostat (suberoylanilide hydroxamic acid, SAHA) for refractory cutaneous T-cell lymphoma (CTCL). Blood 109: 31-39, 2007.

12. Zhang C, Richon V, Ni X, Talpur R and Duvic M: Selective induction of apoptosis by histone deacetylase inhibitor SAHA in cutaneous T-cell lymphoma cells: relevance to mechanism of therapeutic action. J Invest Dermatol 125: 1045-1052, 2005.

13. Gore SD: Combination therapy with DNA methyltransferase inhibitors in hematologic malignancies. Nat Clin Pract Oncol 2 (Suppl 1): S30-S35, 2005.

14. Issa JP and Byrd JC: Decitabine in chronic leukemias. Semin Hematol 42 (Suppl 2): S43-S49, 2005.

15. Batty N, Malouf GG and Issa JP: Histone deacetylase inhibitors as anti-neoplastic agents. Cancer Lett 280: 192-200, 2009.

16. Flotho C, Claus R, Batz C, et al: The DNA methyltransferase inhibitors azacitidine, decitabine and zebularine exert differential effects on cancer gene expression in acute myeloid leukemia cells. Leukemia 23: 1019-1028, 2009.

17. Laurenzana A, Petruccelli LA, Pettersson F, et al: Inhibition of DNA methyltransferase activates tumor necrosis factor alpha-induced monocytic differentiation in acute myeloid leukemia cells. Cancer Res 69: 55-64, 2009.

18. Munster PN, Troso-Sandoval T, Rosen N, Rifkind R, Marks PA and Richon VM: The histone deacetylase inhibitor suberoylanilide hydroxamic acid induces differentiation of human breast cancer cells. Cancer Res 61: 8492-8497, 2001.

19. Shiozawa K, Nakanishi T, Tan M, et al: Preclinical studies of vorinostat (suberoylanilide hydroxamic acid) combined with cytosine arabinoside and etoposide for treatment of acute leukemias. Clin Cancer Res 15: 1698-1707, 2009.

20. Xu WS, Parmigiani RB and Marks PA: Histone deacetylase inhibitors: molecular mechanisms of action. Oncogene 26: 5541-5552, 2007.

21. Buchwald M, Krämer OH and Heinzel T: HDACi - targets beyond chromatin. Cancer Lett 280: 160-167, 2009.

22. Nolan L, Johnson PW, Ganesan A, Packham G and Crabb SJ: Will histone deacetylase inhibitors require combination with other agents to fulfil their therapeutic potential? Br J Cancer 99: 689-694, 2008

23. Gui CY, Ngo L, Xu WS, Richon VM and Marks PA: Histone deacetylase (HDAC) inhibitor activation of $\mathrm{p} 21^{\mathrm{WAF} 1}$ involves changes in promoter-associated proteins, including HDAC1. Proc Natl Acad Sci USA 101: 1241-1246, 2004.

24. Arnold NB, Arkus N, Gunn J and Korc M: The histone deacetylase inhibitor suberoylanilide hydroxamic acid induces growth inhibition and enhances gemcitabine-induced cell death in pancreatic cancer. Clin Cancer Res 13: 18-26, 2007.

25. Eyüpoglu IY, Hahnen E, Buslei R, et al: Suberoylanilide hydroxamic acid (SAHA) has potent anti-glioma properties in vitro, ex vivo and in vivo. J Neurochem 93: 992-999, 2005.
26. Kumagai T, Wakimoto N, Yin D, et al: Histone deacetylase inhibitor, suberoylanilide hydroxamic acid (Vorinostat, SAHA) profoundly inhibits the growth of human pancreatic cancer cells. Int J Cancer 121: 656-665, 2007.

27. Hurd PJ, Whitmarsh AJ, Baldwin GS, et al: Mechanism-based inhibition of C5-cytosine DNA methyltransferases by $2-\mathrm{H}$ pyrimidinone. J Mol Biol 286: 389-401, 1999.

28. Jones PA and Baylin SB: The fundamental role of epigenetic events in cancer. Nat Rev Genet 3: 415-428, 2002.

29. Jackson-Grusby L, Beard C, Possemato R, et al: Loss of genomic methylation causes p53-dependent apoptosis and epigenetic deregulation. Nat Genet 27: 31-39, 2001.

30. Scott SA, Lakshimikuttysamma A, Sheridan DP, Sanche SE, Geyer CR and DeCoteau JF: Zebularine inhibits human acute myeloid leukemia cell growth in vitro in association with p15INK4B demethylation and reexpression. Exp Hematol 35: 263-273, 2007.

31. Gilbert J, Gore SD, Herman JG and Carducci MA: The clinical application of targeting cancer through histone acetylation and hypomethylation. Clin Cancer Res 10: 4589-4596, 2004.

32. Sato N, Fukushima N, Maehara N, et al: SPARC/osteonectin is a frequent target for aberrant methylation in pancreatic adenocarcinoma and a mediator of tumor-stromal interactions. Oncogene 22: 5021-5030, 2003.

33. Sato N, Parker AR, Fukushima N, et al: Epigenetic inactivation of TFPI-2 as a common mechanism associated with growth and invasion of pancreatic ductal adenocarcinoma. Oncogene 24: $850-858,2005$.

34. Fu B, Guo M, Wang S, et al: Evaluation of GATA-4 and GATA-5 methylation profiles in human pancreatic cancers indicate promoter methylation patterns distinct from other human tumor types. Cancer Biol Ther 6: 1546-1552, 2007.

35. Abe T, Toyota M, Suzuki H, et al: Upregulation of BNIP3 by 5 -aza-2'-deoxycytidine sensitizes pancreatic cancer cells to hypoxia-mediated cell death. J Gastroenterol 40: 504-510, 2005.

36. Yamada N, Nishida Y, Tsutsumida H, et al: MUC1 expression is regulated by DNA methylation and histone $\mathrm{H} 3$ lysine 9 modification in cancer cells. Cancer Res 68: 2708-2716, 2008.

37. Yamada N, Hamada T, Goto M, et al: MUC2 expression is regulated by histone $\mathrm{H} 3$ modification and DNA methylation in pancreatic cancer. Int J Cancer 119: 1850-1857, 2006.

38. Vincent A, Ducourouble MP and Van Seuningen I: Epigenetic regulation of the human mucin gene MUC4 in epithelial cancer cell lines involves both DNA methylation and histone modifications mediated by DNA methyltransferases and histone deacetylases. FASEB J 22: 3035-3045, 2008.

39. Yonezawa S, Goto M, Yamada N, Higashi $M$ and Nomoto $M$ : Expression profiles of MUC1, MUC2, and MUC4 mucins in human neoplasms and their relationship with biological behavior. Proteomics 8: 3329-3341, 2008.

40. Omura $\mathrm{N}$ and Goggins $\mathrm{M}$ : Epigenetics and epigenetic alterations in pancreatic cancer. Int J Clin Exp Pathol 2: 310-326, 2009.

41. Furukawa T, Duguid WP, Rosenberg L, Viallet J, Galloway DA and Tsao MS: Long-term culture and immortalization of epithelial cells from normal adult human pancreatic ducts transfected by the E6E7 gene of human papilloma virus 16 . Am J Pathol 148: 1763-1770, 1996.

42. Vonlaufen A, Joshi S, Qu C, et al: Pancreatic stellate cells: partners in crime with pancreatic cancer cells. Cancer Res 68: 2085-2093, 2008.

43. Probst AV, Dunleavy E and Almouzni G: Epigenetic inheritance during the cell cycle. Nat Rev Mol Cell Biol 10: 192-206, 2009.

44. Missiaglia E, Donadelli M, Palmieri M, Crnogorac-Jurcevic T, Scarpa A and Lemoine NR: Growth delay of human pancreatic cancer cells by methylase inhibitor 5-aza-2'-deoxycytidine treatment is associated with activation of the interferon signalling pathway. Oncogene 24: 199-211, 2005.

45. Bolden JE, Peart MJ and Johnstone RW: Anticancer activities of histone deacetylase inhibitors. Nat Rev Drug Discov 5: 769-784, 2006.

46. Butler LM, Agus DB, Scher HI, et al: Suberoylanilide hydroxamic acid, an inhibitor of histone deacetylase, suppresses the growth of prostate cancer cells in vitro and in vivo. Cancer Res 60: 5165-5170, 2000.

47. Butler LM, Zhou X, Xu WS, et al: The histone deacetylase inhibitor SAHA arrests cancer cell growth, up-regulates thioredoxin-binding protein-2, and down-regulates thioredoxin. Proc Natl Acad Sci USA 99: 11700-11705, 2002. 
48. Marks PA and Breslow R: Dimethyl sulfoxide to vorinostat: development of this histone deacetylase inhibitor as an anticancer drug. Nat Biotechnol 25: 84-90, 2007.

49. Henderson C, Mizzau M, Paroni G, Maestro R, Schneider C and Brancolini C: Role of caspases, Bid, and p53 in the apoptotic response triggered by histone deacetylase inhibitors trichostatin-A (TSA) and suberoylanilide hydroxamic acid (SAHA). J Biol Chem 278: 12579-12589, 2003

50. Egger G, Liang G, Aparicio A and Jones PA: Epigenetics in human disease and prospects for epigenetic therapy. Nature 429: 457-463, 2004

51. Polo SE and Almouzni G: Histone metabolic pathways and chromatin assembly factors as proliferation markers. Cancer Lett 220: $1-9,2005$.

52. Koundrioukoff S, Polo S and Almouzni G: Interplay between chromatin and cell cycle checkpoints in the context of ATR/ ATM-dependent checkpoints. DNA Repair (Amst) 3: 969-978, 2004.

53. Graham JS, Kaye SB and Brown R: The promises and pitfalls of epigenetic therapies in solid tumours. Eur J Cancer 45 1129-1136, 2009.

54. Polo SE and Almouzni G: DNA damage leaves its mark on chromatin. Cell Cycle 6: 2355-2359, 2007.

55. Vrana JA, Decker RH, Johnson CR, et al: Induction of apoptosis in U937 human leukemia cells by suberoylanilide hydroxamic acid (SAHA) proceeds through pathways that are regulated by Bcl-2/Bcl-XL, c-Jun, and p21CIP1, but independent of p53. Oncogene 18: 7016-7025, 1999.

56. Abbas T and Dutta A: p21 in cancer: intricate networks and multiple activities. Nat Rev Cancer 9: 400-414, 2009.

57. Mills J, Hricik T, Siddiqi S and Matushansky I: Chromatin structure predicts epigenetic therapy responsiveness in sarcoma. Mol Cancer Ther 10: 313-324, 2011.

58. Yin D, Ong JM, Hu J, et al: Suberoylanilide hydroxamic acid, a histone deacetylase inhibitor: effects on gene expression and growth of glioma cells in vitro and in vivo. Clin Cancer Res 13: 1045-1052, 2007.

59. Vijayaraghavalu S, Dermawan JK, Cheriyath V and Labhasetwar V: Highly synergistic effect of sequential treatment with epigenetic and anticancer drugs to overcome drug resistance in breast cancer cells is mediated via activation of p21 gene expression leading to G2/M cycle arrest. Mol Pharm 10: 337-352, 2013.

60. Carew JS, Nawrocki ST and Cleveland JL: Modulating autophagy for therapeutic benefit. Autophagy 3: 464-467, 2007.

61. Robert T, Vanoli F, Chiolo I, et al: HDACs link the DNA damage response, processing of double-strand breaks and autophagy. Nature 471: 74-79, 2011.
62. Dokmanovic M, Perez G, Xu W, et al: Histone deacetylase inhibitors selectively suppress expression of HDAC7. Mol Cancer Ther 6: 2525-2534, 2007.

63. Mitsiades CS, Mitsiades NS, McMullan CJ, et al: Transcriptional signature of histone deacetylase inhibition in multiple myeloma: biological and clinical implications. Proc Natl Acad Sci USA 101: 540-545, 2004

64. Cooper AL, Greenberg VL, Lancaster PS, van Nagell JR Jr, Zimmer SG and Modesitt SC: In vitro and in vivo histone deacetylase inhibitor therapy with suberoylanilide hydroxamic acid (SAHA) and paclitaxel in ovarian cancer. Gynecol Oncol 104: 596-601, 2007.

65. Nimmanapalli R, Fuino L, Stobaugh C, Richon V and Bhalla K: Cotreatment with the histone deacetylase inhibitor suberoylanilide hydroxamic acid (SAHA) enhances imatinib-induced apoptosis of Bcr-Abl-positive human acute leukemia cells Blood 101: 3236-3239, 2003.

66. Holzman DC: Pancreatic cancer: will incremental advances begin to make a difference? J Natl Cancer Inst 102: 1821-1823, 2010.

67. Neoptolemos JP, Dunn JA, Stocken DD, et al: Adjuvant chemoradiotherapy and chemotherapy in resectable pancreatic cancer: a randomised controlled trial. Lancet 358: 1576-1585, 2001.

68. Neoptolemos JP, Stocken DD, Bassi C, et al: Adjuvant chemotherapy with fluorouracil plus folinic acid vs gemcitabine following pancreatic cancer resection: a randomized controlled trial. JAMA 304: 1073-1081, 2010.

69. O'Reilly EM: Refinement of adjuvant therapy for pancreatic cancer. JAMA 304: 1124-1125, 2010

70. Mohammed A, Janakiram NB, Li Q, et al: The epidermal growth factor receptor inhibitor gefitinib prevents the progression of pancreatic lesions to carcinoma in a conditional LSL-KrasG12D/+ transgenic mouse model. Cancer Prev Res (Phila) 3: 1417-1426, 2010.

71. Appleton K, Mackay HJ, Judson I, et al: Phase I and pharmacodynamic trial of the DNA methyltransferase inhibitor decitabine and carboplatin in solid tumors. J Clin Oncol 25: 4603-4609, 2007.

72. Venturelli S, Berger A, Weiland T, et al: Dual antitumour effect of 5-azacytidine by inducing a breakdown of resistance-mediating factors and epigenetic modulation. Gut 60: 156-165, 2011.

73. Shakya R, Gonda T, Quante M, et al: Hypomethylating therapy in an aggressive stroma-rich model of pancreatic carcinoma. Cancer Res 73: 885-896, 2013. 